\title{
PELATIHAN KEBERSYUKURAN UNTUK MENINGKATKAN KUALITAS HIDUP GURU SEKOLAH INKLUSI
}

\section{GRATITUDE TRAINING TO IMPROVE INCLUSION TEACHER'S QUALITY OF LIFE}

\author{
Dwiva Aditya Putri \\ Sukarti \\ Mira A. Rachmawati \\ Fakultas Psikologi dan Ilmu Sosial Budaya Universitas Islam Indonesia Yogyakarta \\ Email: dwivaadityaputri@gmail.com
}

\begin{abstract}
The purpose of this study is to improve inclusion teacher's quality of life by delivering gratitude training. There were 16 teacherswho teach at inclusion's elementary school in Yogyakarta, participated inthis study. They had moderate and low score on quality of life's scale. Data were collected with observation, interview, and quality of life's scale. The result showed that there was a significant difference between subjects who received gratitude training and subjects who did not receive gratitude training $(F=8.082, p$ $=0.002 ; p<0.05)$. Gratitude training was effective to improved inclusion teacher's quality of life.
\end{abstract}

Key words: quality of life, gratitude, inclusion teachers

\begin{abstract}
ABSTRAK
Tujuan penelitian ini adalah untuk meningkatkan kualitas hidup guru sekolah inklusi melalui pelatihan kebersyukuran. Subjek penelitian adalah 16 guru yang mengajar di sekolah dasar inklusi ' $X$ ' dan ' $Y$ ' di Kota Yogyakarta yang memiliki skor kualitas hidup yang sedang dan rendah berdasarkan skala kualitas hidup. Penelitian ini menggunakan metode observasi, wawancara, dan skala kualitas hidup. Hasil penelitian menunjukkan ada perbedaan yang signifikan antara subjek yang mengikuti pelatihan kebersyukuran dan subjek yang tidak mengikuti pelatihan kebersyukuran. Hal ini ditunjukkan dengan adanya perbedaan yang signifikan antara skor prates dan paskates kualitas hidup pada kelompok eksperimen dan kontrol $(\mathrm{F}=$ 8.082, $\mathrm{p}=0.002 ; \mathrm{p}<0.05)$. Maka dapat disimpulkan bahwa pelatihan kebersyukuran efektif dalam meningkatkan kualitas hidup guru inklusi.
\end{abstract}

Kata Kunci: kualitas hidup, kebersyukuran, guru sekolah inklusi

Berdasarkan Undang-Undang Republik Indonesia Nomor 20 Tahun 2003 tentang sistem pendidikan nasional, diketahui pendidikan merupakan usaha sadar dan terencana untuk mewujudkan suasana belajar dan proses pembelajaran agar peserta didik secara aktif mengembangkan potensi dirinya untuk memiliki kekuatan spiritual keagamaan, pengendalian diri, kepribadian, kecerdasan, akhlak mulia, serta keterampilan yang diperlukan dirinya, masyarakat, bangsa 
dan negara. Prinsip penyelenggaran pendidikan yang tercantum pada pasal 4 ayat 1 Undang-Undang Nomor 20 Tahun 2003 menyatakan bahwa pendidikan diselenggarakan secara demokratis dan berkeadilan serta tidak diskriminatif dengan menjunjung tinggi hak asasi manusia, nilai keagamaan, nilai kultural, dan kemajemukan bangsa (Elisa \& Wrastari, 2013; Stark, Gordon-Burns, Purdue, Rarere-Briggs, \& Turnock, 2010).

Meski undang-undang telah secara tegas mengatur pemerataan hak dan kewajiban bagi setiap warga negara untuk mengakses pendidikan, diskriminasi dalam bidang pendidikan masih kerap terjadi khususnya terhadap anak berkebutuhan khusus. Salah satu program pendidikan yang dilakukan untuk mengatasi isu diskriminasi dalam bidang pendidikan adalah pendidikan inklusi (Elisa \& Wrastari, 2013; Ni'matuzahroh, 2015).

Praktek inklusi merupakan tantangan baru bagi pengelola sekolah. Institusi pendidikan perlu melakukan perubahan terhadap program pendidikan untuk merespon kebutuhan siswa dalam pembelajaran,terlebih mereka yang memiliki kebutuhan khusus. Guru merupakan peran yang penting dalam sekolah. Seorang guru diharapkan dapat memberikan kehidupan kelas agar menjadi lebih hangat dan pada waktu yang bersamaan dapat memberikan pemahaman kepada murid yang lain untuk dapat saling berinteraksi (Elisa \& Wrastari, 2013; Arrofiq, 2013; Hutton, 2008; Kongchao, Min, Yongbo, \& Xiaoping, 2015; Chadha \& Pandey, 2015). Guru dituntut dapat memahami kurikulum yang akan diberikan dan berpartisipasi penuh agar anak berkebutuhan khusus mendapatkan pendidikan yang baik. Namun, pada kenyataannya, masih banyak guru inklusi yang belum berpartisipasi utuh dalam mendidik anak berkebutuhan khusus dan lebih condong memilih mengajar anak normal.

Menjadi guru inklusi memang tidak mudah. Salah satu penyebabnya adalah beban mengajar anak berkebutuhan khusus dirasa lebih berat dibandingkan dengan anak normal (Stark, Gordon-Burns, Purdue, Rarere-Briggs, \& Turnock, 2010). Studi di Brazil setidaknya menguatkan hal tersebut, guru dipandang sebagai profesi yang memiliki tingkat kelelahan emosional yang tinggi. Berdasarkan penelitian epidemiologi mengindikasikan bahwa $26 \%$ guru di Brazil menunjukkan ting-kat ketegangan emosional yang tidak sesuai (Damasio, Malo, \& Silva, 2013).

Sumber stresor yang terjadi pada guru cukup beragam, yaitu bisa berasal dari perilaku siswa yang tidak sesuai, masalah disiplin pada siswa, motivasi 
kerja yang rendah, beban kerja yang berat dan tekanan waktu, konflik peran dan keambiguan peran, konflik dengan staf, dan tekanan serta kritik dari orang tua. Setiap guru melakukan cara yang berbeda untuk mengatasi stresor tersebut. Ada yang mengalami frustrasi ringan, kecemasan, dan kelelahan emosional. Ada juga beberapa guru yang mengalami psikosomatis berat dan muncul gejala depresi yang membutuhkan intervensi terapeutik. Beberapa guru juga mengalami burnout atas stresor yang menimpa dirinya (Chan, 2010).

Banyak guru yang mengalami stres di sekolah. Mereka merasa burned-out, tidak bahagia, atau tidak puas karena faktor tingginya rasio guru-murid, kondisi sekolah yang tidak menyenangkan (hubungan dengan rekan kerja yang kurang baik, adanya anak berkebutuhan khusus dalam kelas), dan gaji yang rendah. Berdasarkan penelitian yang telah dilakukan pada 16.723 guru di Turki, 66,9\% guru mengalami sindrom burn-out, 37\% mengalami stres, 18,6\% merasa tidak berguna, dan 3,19\% terlibat dalam kekerasan pada orang tua atau siswa. Pada penelitian lain, guru merasakan sindrom burn-out jika dibandingkan dengan pekerjaan lain (Ilgan, OzuCengis, Ata, \& Akram, 2015).
Hal ini juga sesuai dengan data awal yang diperoleh dari guru di salah satu sekolah inklusi di Yogyakarta. Guru merasakan tuntutan dan tekanan yang lebih besar untuk mengajar di sekolah inklusi karena dalam satu kelas terdapat lebih dari 50\% anak berkebutuhan khusus. Pemahaman mereka tidak sebanding dengan keterampilan yang mereka miliki dalam mengajar anak berkebutuhan khusus. Guru merasa belum terbiasa dalam mengajar anak berkebutuhan khusus, sehingga akhirnya guru mengajar anak berkebutuhan khusus seperti mengajar anak normal. Selain itu, tekanan lain yang dirasakan guru inklusi adalah tuntutan membuat laporan. Guru dituntut untuk membuat RPP dan silabus. Selain itu mereka juga membuat Program Pendidikan Individual untuk anak berkebutuhan khusus. Karena adanya beragam tuntutan tersebut, akhirnya guru bisa mengalami burn-out. Selain itu, guru juga merasa mudah emosional dalam mengajar di kelas inklusi, dan akhirnya berdampak pada cara mengajar guru dan kehidupan sosial guru.

Pendidikan inklusi memiliki kontribusi dalam dinamika kelas, fungsi dari kurikulum, dan juga dapat mengubah harapan guru. Dalam pendidikan inklusi, ketika populasi kelas berubah dan rentang kemampuan siswa meningkat, 
guru harus mampu menyesuaikan program mereka dan menyesuaikan harapan mereka atas hasil yang siswa akan peroleh. Hal ini memerlukan pemeriksaan yang hati-hati dan introspeksi guru atas harapan dari hasil yang siswa peroleh. Sikap guru menjadi salah satu hal yang penting dalam memberikan keberhasilan dari program inklusi (Hull, 2005; McKeating, 2013). Guru yang memiliki pandangan positif terhadap pendidikan inklusi merupakan bukti bahwa mereka memiliki keinginan untuk beradaptasi dengan kelas inklusi. Sebaliknya, guru yang memiliki sikap negatif memiliki harapan yang rendah terhadap siswa berkebutuhan khusus. Jumlah anak berkebutuhan khusus yang masuk di sekolah inklusi meningkat, konsekuensinya guru inklusi harus siap menghadapi tantangan yang lebih dalam menangani anak-anak berkebutuhan khusus (Muwana, 2013).

Berdasarkan kondisi tersebut, mengajar memberikan dampak yang signifikan pada tingkat kesejahteraan psikologis dan kualitas hidup guru. Beberapa literatur ilmiah menjelaskan bahwa kondisi mengajar yang dapat menurunkan kualitas hidup guru dibagi menjadi beberapa kategori, yaitu: (1) administratif (beban kerja yang tinggi; rendahnya otonomi, rendahnya partisipasi dalam pengambilan keputusan, sedikitnya waktu untuk menyelesaikan tugas); (2) finansial (rendahnya gaji dan membutuhkan beberapa pekerjaan); (3) ergonomik (kebisingan yang tinggi di kelas, rendahnya pencahayaan, jumlah siswa yang tidak sesuai tiap kelas); dan (4) sosial (rendahnya kemampuan sosial dengan kolega, kekerasan, penggunaan obat-obatan di sekolah), dan lain-lain (Damasio, Malo, \& Silva, 2013).

Hal ini sesuai dengan keadaan guru di SD inklusi ' $X$ ' yang merasakan lebih emosional ketika mengajar anakanak berkebutuhan khusus. Berdasarkan hasil wawancara terdapat indikasi bahwa guru-guru SDN inklusi ' $X$ ' memiliki kualitas hidup yang rendah, karena guruguru tersebut memiliki persepsi yang buruk terhadap pekerjaannya, merasa lebih emosional ketika mengajar anak berkebutuhan khusus di sekolah inklusi. Mereka juga merasa beban kerja guru inklusi lebih berat. Selain itu, mereka juga tidak puas dengan gaji yang mereka peroleh. Hal ini berhubungan dengan kualitas hidup yang merupakan persepsi individu terhadap posisinya dalam kehidupan.

WHO (1997) mendefinisikan kualitas hidup adalah persepsi individu terhadap posisinya di kehidupan, dalam konteks budaya dan sistem nilai yang mereka jalani. Kualitas hidup setiap 
orang dapat berbeda-beda, karena kualitas hidup bersifat subjektif. Hal ini sesuai dengan data awal yang diperoleh bahwa guru yang mempersepsikan kualitas hidup yang baik adalah dengan mendapatkan penghasilan yang cukup, dapat mengerjakan pekerjaan dengan baik tanpa ditunda-tunda, memperoleh cinta dan afeksi yang cukup dari lingkungan sosial dan keluarga, serta memiliki tubuh sehat serta tidur yang cukup. Hal ini juga sesuai dengan pendapat WHO (1997) yang menyatakan bahwa kualitas hidup merupakan hal yang subjektif dan dapat dilihat dari berbagai aspek, yaitu kesehatan fisik, psikis, hubungan sosial, dan lingkungan. Kualitas hidup merupakan salah satu hal penting dalam harapan hidup.

Semua aspek yang berhubungan dengan kesejahteraan adalah berasal dari kualitas hidup (Damasio, Malo, \& Silva, 2013; Shabani \& Shamir, 2014). Artinya, seseorang akan memiliki kualitas hidup yang tinggi apabila ia mempersepsikan dirinya baik dengan segala apa yang dimilikinya. Kualitas hidup seseorang akan baik apabila ia bersyukur dengan segala apa yang dimilikinya.

Sikap syukur rmerupakan bagian dari cara untuk memaknai apa yang telah dikerjakan sebagai karya nyata manusia. Sikap syukur menjadi jembatan antara masalah dengan solusi bagi para guru di dalam menjalani kehidupan. Melalui sikap mensyukuri segala sesuatu yang sudah diterima, baik secara materi maupun nonmateri (batin), maka manusia akan menemukan makna hidup yang sesungguhnya, yaitu sesuatu yang bisa membuat seseorang menjadi lebih berarti dan berharga dalam kehidupan yang bermuara pada kebahagiaan (Arrofiq, 2013).

Penelitian Emmons dan McCullough (2003) menunjukkan rasa syukur merupakan bagian dari perilaku berketuhanan, bagaimana cara seseorang mampu untuk berterima kasih kepada Tuhannya. Hasil riset mereka menunjukkan, bahwa rasa syukur itu mempengaruhi kesejahteraan fisik dan psikologis. Salah satunya adalah saat orang yang mendokumentasikan rasa syukurnya secara mingguan, mereka merasa hidupnya lebih baik dan lebih optimis dalam menghadapi hari-hari berikutnya. Hasil yang lain, hanya dalam dua bulan, orang yang membuat daftar syukur lebih mengalami kemajuan dalam mencapai sasaran dan tujuan pribadi (akademis, hubungan interpersonal, kesehatan). Orang yang bersyukur dilaporkan memiliki tingkatan yang lebih tinggi dalam emosi positif, kepuasan hidup, vitalitas, optimisme, dan lebih rendah dalam tingkat depresi atau stres. 
Rasa syukur memperkaya rasa bahagia dalam tingkatan yang lebih tinggi daripada turunnya emosi negatif. Rasa syukur lebih membuat bahagia daripada menghilangkan kesedihan. Orang yang bersyukur memposisikan barang-barang materi sebagai tidak terlalu penting. Mereka lebih melihatnya sebagai milik bersama. Mereka tidak mudah mendengki kepada orang lain, dan lebih menyukai berbagi dengan orang lain (Wicaksono, 2013).

Rasa kebersyukuran dapat menjadi landasan penting dalam efikasi diri pada guru, seseorang akan bahagia dan mempunyai rasa terima kasih dari apa yang dicapainya sehingga orang tersebut mau dan mampu untuk bertahan pada pekerjaannya. Meskipun dengan pendapatan yang rendah serta faktor eksternal yang kurang mendukung, seorang guru yang memiliki rasa kebersyukuran akan senantiasa bahagia menjalani pekerjaannya serta dapat memengaruhi bagaimana seseorang berperilaku setelahnya. Kurangnya rasa kebersyukuran tersebut akan membuatindividu merasa senantiasa kurangdalam berbagai hal. Orang tersebut kurang memiliki kemauan serta inisiatif untuk berusaha menjadi lebih baik dan cenderung menerima apa adanya atau menjadi terpaksa melakukan pekerjaannya (Wicaksono, 2013). Dam- pak dari perasaan bersyukur dapat berkembang menjadi reaksi atau tanggapan yang berwujud sebuah sikap. Oleh sebab itu, syukur dapat mendorong manusia untuk menerima keadaan yang ada (Wicaksono, 2013).

Bersyukur menumbuhkan pengalaman hidup yang positif dari pengalaman hidup atau situasi yang dihadapi, sehingga seseorang dapat mengeluarkan kepuasan secara maksimal dan menikmati keadaan mereka. Bersyukur juga merupakan strategi koping. Dalam bersyukur seseorang menafsirkan secara positif permasalahan hidup (Arief \& Habibah, 2015).

Berterima kasih atas kehidupan dapat menimbulkan ketenangan pikiran, kebahagiaan, kesehatan fisik, dan hubungan pribadi lebih memuaskan (Emmons \& McCullough, 2003). Sesuai dengan penelitian Froh, Seffick, dan Emmons (2008) diketahui bahwa pandangan kebersyukuran tidak memerlukan kehidupan yang penuh kenyamanan materi melainkan sikap interior bersyukur terlepas dari kondisi kehidupan. Penelitian pada orang dewasa menunjukkan bahwa individu yang sering merasakan dan mengungkapkan rasa terima kasih akan lebih menikmati pekerjaan, lebih optimis dan energik, dan lebih membantu atau mendukung orang lain 
daripada orang yang tidak meng-alami rasa bersyukur.

Berdasarkan paparan tersebut, peneliti ingin mengetahui efektivitas pelatihan kebersyukuran untuk meningkatkan kualitas hidup guru inklusi. Pelatihan ini bertujuan untuk meningkatkan kebersyukuran guru inklusi agar kualitas hidup guru inklusi meningkat.

\section{METODE PENELITIAN}

\section{Desain Penelitian}

Desain penelitian ini ialah pretestposttest control group design, yaitu dilakukan pengukuran sebelum dan sesudah pemberian perlakuan pada kedua kelompok. Pada desain ini dilakukan randomisasi untuk menyetarakan kelompok eksperimen dan kontrol. Randomisasi yang dilakukan adalah randomisasi kelompok, yaitu masing-masing sekolah akan dipilih guru yang akan menjadi kelompok eksperimen dan kontrol.

\section{Subjek Penelitian}

Partisipan penelitian ini adalah 16 guru yang mengajar di sekolah dasar inklusi ' $X$ ' dan ' $Y$ ' di Kota Yogyakarta dan memiliki skor kualitas hidup dengan kategori sedang dan rendah.

\section{Metode Pengumpulan Data}

Metode pengumpulan data dalam penelitian ini ialah dengan menggunakan observasi, wawancara, dan skala kualitas hidup. Skala yang digunakan ialah skala kualitas hidup yang dimodifikasi dari skala WHOQOL dan dibuat berdasarkan dimensi kualitas hidup, yaitu kesehatan fisik, psikologis, hubungan sosial, dan lingkungan (WHO, 1997).

Skala WHOQOL ini memiliki validitas dan reliabilitas yang baik. Alat ukur ini sudah diuji coba oleh WHO di 20 negara dan sudah diterjemahkan ke dalam berbagai bahasa, termasuk bahasa Indonesia. Alat ukur ini diuji coba kepada 11.830 orang di 20 negara. Subjek terdiri dari beragam usia, pekerjaan, status perkawinan, dan keadaan kesehatan. Nilai alpha cronbach yang diperoleh pada masing-masing aspek antara lain: kesehatan fisik $(0,82)$, psikologis $(0,81)$, lingkungan $(0,80)$, dan hubungan sosial $(0,68)$. Nilai alpha cronbach pada semua aspek berkisar antara 0-1, yang artinya alat ukur ini memiliki reliabilitas yang baik. Korelasi item-domain berkisar antara 0,48-0,7 untuk domain kesehatan fisik, 0,5-0,65 untuk domain psikologis, 0,45-0,57 untuk domain hubungan sosial, dan 0,47-0,56 untuk domain lingkungan. Skala ini sudah digunakan di berbagai 
penelitian, yaitu penelitian Chadha dan Pandey (2015) mengenai kualitas hidup guru pemerintah dan non-pemerintah; penelitian Yuliati, Baroya, dan Ririanty (2014) mengenai kualitas hidup lansia; penelitian Putri, Wati, dan Ariyanto (2014) mengenai kualitas hidup wanita menopause; penelitian Alves, Salim, Martinez, Passos, Carlo, dan Scarpelini (2009) mengenai kualitas hidup korban trauma; dan penelitian Damasio, Melo, dan Silva (2013) mengenai kualitas hidup guru.

\section{Prosedur Intervensi}

Intervensi yang diberikan pada penelitian ini adalah pelatihan kebersyukuran. Pelatihan kebersyukuran ini melatih guru sekolah inklusi agar dapat bersyukur dengan hati, lisan, dan perbuatan. Pelatihan ini dilaksanakan dalam dua kali pertemuan dalam sebelas sesi dengan total waktu 990 menit.

Sebelum pelatihan dilakukan, modul intervensi kebersyukuran disusun berdasarkan aspek-aspek kebersyukuran Al-Jauziyyah (2010), yaitu bersyukur dengan hati, lisan, dan perbuatan. Modul yang telah disusun kemudian dievaluasi melalui professional judgment untuk kemudian dilakukan ujicoba.

\section{Teknik Analisis Data}

Teknik analisis data yang digunakan untuk menguji hipotesis adalah analisis statistik anava campuran untuk mengetahui ada tidaknya perbedaan antara sebelum diberikan perlakuan (pretest), sesudah perlakuan (post-test) dan tindak lanjut (follow up) dalam sebuah kelompok.

\section{HASIL PENELITIAN}

\section{Deskripsi Data Penelitian}

Deskripsi data penelitian diperoleh berdasarkan pengisian skala kualitas hidup sebelum pelatihan (prates), setelah pelatihan (paskates), dan dua minggu setelah pelatihan (tindak lanjut). Deskripsi data kelompok eksperimen dan kelompok kontrol dapat dilihat pada tabel berikut ini: 
Tabel 1. Deskripsi Data Kelompok Eksperimen dan Kelompok Kontrol

\begin{tabular}{|c|c|c|c|c|c|c|c|}
\hline \multirow{4}{*}{ Kategori } & \multirow{4}{*}{$\begin{array}{c}\text { Norma } \\
\text { Persentil }\end{array}$} & \multicolumn{6}{|c|}{ Variabel Penelitian } \\
\hline & & \multirow{2}{*}{\multicolumn{2}{|c|}{$\begin{array}{c}\text { Pra Intervensi } \\
\text { Kelompok }\end{array}$}} & \multirow{2}{*}{\multicolumn{2}{|c|}{$\begin{array}{c}\text { Paska Intervensi } \\
\text { Kelompok }\end{array}$}} & \multirow{2}{*}{\multicolumn{2}{|c|}{$\begin{array}{c}\text { Tindak Lanjut } \\
\text { Kelompok }\end{array}$}} \\
\hline & & & & & & & \\
\hline & & $\begin{array}{c}\text { Eksperi- } \\
\text { men }\end{array}$ & Kontrol & $\begin{array}{c}\text { Eksperi- } \\
\text { men }\end{array}$ & Kontrol & $\begin{array}{c}\text { Eksperi- } \\
\text { men }\end{array}$ & Kontrol \\
\hline Rendah & $x<63$ & 1 & 1 & 0 & 0 & 0 & 2 \\
\hline Sedang & $\begin{array}{c}63 \leq X< \\
79\end{array}$ & 7 & 7 & 4 & 8 & 4 & 6 \\
\hline Tinggi & $x \geq 79$ & 0 & 0 & 4 & 0 & 4 & 0 \\
\hline \multicolumn{2}{|c|}{ Jumlah } & 8 & 8 & 8 & 8 & 8 & 8 \\
\hline
\end{tabular}

Berdasarkan deskripsi data diatas, dapat terlihat perbedaan jumlah peserta sebelum pelatihan, paska pelatihan, dan saat tindak lanjut antara kelompok eksperimen dan kelompok kontrol. Pada kelompok eksperimen sebelum pelatihan dan setelah pelatihan mengalami peningkatan.

\section{Hasil Uji Asumsi}

Uji asumsi dilakukan dengan menggunakan uji normalitas dan uji homogenitas. Berikut ini adalah hasil uji normalitas.

Tabel 2. Uji Normalitas

\begin{tabular}{cccc}
\hline $\begin{array}{c}\text { Kelompok } \\
\text { Penelitian }\end{array}$ & \multicolumn{2}{c}{ Kolmogorov-Smirnov } & Keterangan \\
\cline { 2 - 3 } Eksperimen & Statistik & Sig & $\mathrm{P}>0.05$ \\
& 0.531 & 0.940 & \begin{tabular}{c} 
(Signifikan) \\
\hline Kontrol
\end{tabular} \\
\hline 0.462 & 0.983 & $\begin{array}{c}\mathrm{P}>0.05 \\
\text { (Signifikan) }\end{array}$ \\
\hline
\end{tabular}

Uji normalitas yang menggunakan teknik Kolmogorov-Smirnov pada kelompok eksperimen menunjukkan skor 0.531 $(P=0.940, P>0.05)$. Hal ini berarti sebaran data dinyatakan normal untuk kelompok eksperimen. Sementara pada kelompok kontrol menunjukkan skor $0.462(P=0.983, P>0.05)$. Hal ini juga berarti sebaran data pada kelompok kontrol dinyatakan normal. 
a. Uji Homogenitas

$$
\text { Tabel 3. Uji Homogenitas }
$$

\begin{tabular}{cc}
\hline Box's Test of Equality of Covariance Matrices $^{\mathrm{a}}$ \\
\hline Box's M & 8.155 \\
F & 1.038 \\
df1 & 6 \\
df2 & $1.420 \mathrm{E} 3$ \\
Sig. & .399 \\
\hline
\end{tabular}

Berdasarkan data dapat dilihat signifikansi sebesar $0.399(p>0.05)$. homogenitas skor kualitas hidup pada Dengan demikian, dapat disimpulkan kelompok eksperimen dan kelompok bahwa skor kualitas hidup pada masingkontrol. Data diatas menunjukkan nilai masing kelompok bersifat homogen.

\section{Hasil Uji Hipotesis}

Tabel 4. Hasil Mauchly's Test of Sphericity

\begin{tabular}{lrrrrrrrr}
\hline Within & & & & \multicolumn{4}{c}{ Epsilon $^{\text {a }}$} \\
$\begin{array}{l}\text { Subjects } \\
\text { Effect }\end{array}$ & Mauchly's & Approx. Chi- & & \multicolumn{2}{c}{$\begin{array}{c}\text { Greenhouse- } \\
\text { Huynh- }\end{array}$} & Lower- \\
\hline Time & W & Square & df & Sig. & Geisser & Feldt & bound \\
\hline
\end{tabular}


Tabel 5. Hasil Tests of Within-Subjects Effects

\begin{tabular}{|c|c|c|c|c|c|c|c|}
\hline Source & & $\begin{array}{l}\text { Type III } \\
\text { Sum of } \\
\text { Squares }\end{array}$ & df & Mean Square & $\mathrm{F}$ & Sig. & $\begin{array}{l}\text { Partial Eta } \\
\text { Squared }\end{array}$ \\
\hline \multirow[t]{4}{*}{ time } & $\begin{array}{l}\text { Sphericity } \\
\text { Assumed }\end{array}$ & 362.625 & 2 & 181.312 & 8.857 & .001 & .388 \\
\hline & $\begin{array}{l}\text { Greenhouse- } \\
\text { Geisser }\end{array}$ & 362.625 & 1.923 & 188.607 & 8.857 & .001 & .388 \\
\hline & Huynh-Feldt & 362.625 & 2.000 & 181.312 & 8.857 & .001 & .388 \\
\hline & Lower-bound & 362.625 & 1.000 & 362.625 & 8.857 & .010 & .388 \\
\hline \multirow[t]{4}{*}{ time $*$ group } & $\begin{array}{l}\text { Sphericity } \\
\text { Assumed }\end{array}$ & 330.875 & 2 & 165.438 & 8.082 & .002 & .366 \\
\hline & $\begin{array}{l}\text { Greenhouse- } \\
\text { Geisser }\end{array}$ & 330.875 & 1.923 & 172.094 & 8.082 & .002 & .366 \\
\hline & Huynh-Feldt & 330.875 & 2.000 & 165.438 & 8.082 & .002 & .366 \\
\hline & Lower-bound & 330.875 & 1.000 & 330.875 & 8.082 & .013 & .366 \\
\hline \multirow[t]{4}{*}{ Error(time) } & $\begin{array}{l}\text { Sphericity } \\
\text { Assumed }\end{array}$ & 573.167 & 28 & 20.470 & & & \\
\hline & $\begin{array}{l}\text { Greenhouse- } \\
\text { Geisser }\end{array}$ & 573.167 & 26.917 & 21.294 & & & \\
\hline & Huynh-Feldt & 573.167 & 28.000 & 20.470 & & & \\
\hline & Lower-bound & 573.167 & 14.000 & 40.940 & & & \\
\hline
\end{tabular}

Berdasarkan data diatas diperoleh $\mathrm{F}$ menunjukkan bahwa perubahan skor $=8.082(\mathrm{p}=0.002, \mathrm{p}<0.05)$ artinya pretest menuju posttest pada kedua terdapat interaksi antara waktu (pretest, kelompok adalah berbeda secara posttest, dan follow up) dan kelompok signifikan. (eksperimen dan kontrol). Interaksi 
Tabel 6. Hasil Pairwise Comparisons

\begin{tabular}{|c|c|c|c|c|c|c|c|}
\hline \multirow[b]{2}{*}{ group } & \multirow[b]{2}{*}{ (I) time } & \multirow[b]{2}{*}{ (J) time } & \multirow{2}{*}{$\begin{array}{c}\text { Mean } \\
\text { Difference (I-J) }\end{array}$} & \multirow[b]{2}{*}{ Std. Error } & \multirow[b]{2}{*}{ Sig. ${ }^{a}$} & \multicolumn{2}{|c|}{$\begin{array}{l}\text { 95\% Confidence Interval for } \\
\text { Difference }^{\mathrm{a}}\end{array}$} \\
\hline & & & & & & Lower Bound & Upper Bound \\
\hline \multirow[t]{6}{*}{1} & 1 & 2 & $-9.500^{*}$ & 2.026 & .000 & -13.846 & -5.154 \\
\hline & & 3 & $-12.625^{*}$ & 2.403 & .000 & -17.779 & -7.471 \\
\hline & 2 & 1 & $9.500^{*}$ & 2.026 & .000 & 5.154 & 13.846 \\
\hline & & 3 & -3.125 & 2.339 & .203 & -8.142 & 1.892 \\
\hline & 3 & 1 & $12.625^{*}$ & 2.403 & .000 & 7.471 & 17.779 \\
\hline & & 2 & 3.125 & 2.339 & .203 & -1.892 & 8.142 \\
\hline \multirow[t]{6}{*}{2} & 1 & 2 & -.625 & 2.026 & .762 & -4.971 & 3.721 \\
\hline & & 3 & -.125 & 2.403 & .959 & -5.279 & 5.029 \\
\hline & 2 & 1 & .625 & 2.026 & .762 & -3.721 & 4.971 \\
\hline & & 3 & .500 & 2.339 & .834 & -4.517 & 5.517 \\
\hline & 3 & 1 & .125 & 2.403 & .959 & -5.029 & 5.279 \\
\hline & & 2 & -.500 & 2.339 & .834 & -5.517 & 4.517 \\
\hline
\end{tabular}

Tabel diatas menunjukkan bahwa $(\mathrm{MD}=-0.625, \mathrm{p}=0.762 ; \mathrm{p}<0.05)$. perubahan kualitas hidup pada kelompok Hal ini menunjukkan bahwa pelatihan eksperimen (group 1) adalah signifikan kebersyukuran yang diberikan pada $(M D=-9.5, p=0.00 ; p<0.05)$ kelompok eksperimen efektif dalam sedangkan perubahan kualitas hidup meningkatkan kualitas hidup guru pada kelompok kontrol tidak signifikan inklusi. 
Tabel 7. Hasil Multivariate Tests

\begin{tabular}{|c|c|c|c|c|c|c|c|}
\hline group & & Value & $\mathrm{F}$ & Hypothesis df & Error df & Sig. & $\begin{array}{c}\text { Partial Eta } \\
\text { Squared }\end{array}$ \\
\hline \multirow[t]{4}{*}{1} & Pillai's trace & .710 & $15.931^{\mathrm{a}}$ & 2.000 & 13.000 & .000 & .710 \\
\hline & Wilks' lambda & .290 & $15.931^{\mathrm{a}}$ & 2.000 & 13.000 & .000 & .710 \\
\hline & Hotelling's trace & 2.451 & $15.931^{\mathrm{a}}$ & 2.000 & 13.000 & .000 & .710 \\
\hline & Roy's largest root & 2.451 & $15.931^{\mathrm{a}}$ & 2.000 & 13.000 & .000 & .710 \\
\hline \multirow[t]{4}{*}{2} & Pillai's trace & .007 & $.049^{\mathrm{a}}$ & 2.000 & 13.000 & .953 & .007 \\
\hline & Wilks' lambda & .993 & $.049^{\mathrm{a}}$ & 2.000 & 13.000 & .953 & .007 \\
\hline & Hotelling's trace & .007 & $.049^{a}$ & 2.000 & 13.000 & .953 & .007 \\
\hline & Roy's largest root & .007 & $.049^{a}$ & 2.000 & 13.000 & .953 & .007 \\
\hline
\end{tabular}

Berdasarkan data diatas dapat dilihat bahwa nilai Partial Eta Squared pada kelompok eksperimen sebesar 0.71, artinya pelatihan kebersyukuran yang diberikan meningkatkan kualitas hidup guru inklusi sebesar $71 \%$.

Berikut merupakan hasil analisis aspek-aspek kualitas hidup, yaitu aspek fisik, psikologis, sosial, dan lingkungan.

Tabel 8. Hasil Analisis Aspek-aspek Kualitas Hidup

\begin{tabular}{|c|c|c|c|c|c|c|c|}
\hline \multirow{3}{*}{ Aspek } & \multicolumn{2}{|c|}{ Time*Group } & \multicolumn{4}{|c|}{ Pairwise Comparison } & \multirow{3}{*}{$\begin{array}{c}\text { Partial Eta } \\
\text { Squared }\end{array}$} \\
\hline & \multirow[t]{2}{*}{$\mathbf{F}$} & \multirow[t]{2}{*}{ Sig } & \multicolumn{2}{|c|}{$\begin{array}{c}\text { Mean Difference } \\
(\mathrm{I}-\mathrm{J})\end{array}$} & \multicolumn{2}{|c|}{ Sig } & \\
\hline & & & KE & KK & KE & KK & \\
\hline \multirow{2}{*}{ Fisik } & \multirow{2}{*}{4.266} & \multirow{2}{*}{0.024} & \multirow{2}{*}{-2} & \multirow{2}{*}{0.25} & 0.00 & 0.63 & \multirow{2}{*}{$52.8 \%$} \\
\hline & & & & & 2 & 4 & \\
\hline \multirow{2}{*}{ Psikologis } & \multirow{2}{*}{4.589} & \multirow{2}{*}{0.019} & \multirow{2}{*}{-2.5} & \multirow{2}{*}{0.00} & 0.00 & & \multirow{2}{*}{$48 \%$} \\
\hline & & & & & 3 & 1 & \\
\hline \multirow{2}{*}{ Sosial } & \multirow{2}{*}{3.556} & \multirow{2}{*}{0.042} & \multirow{2}{*}{-0.625} & \multirow{2}{*}{0.125} & 0.12 & 0.75 & \multirow{2}{*}{$42.1 \%$} \\
\hline & & & & & 8 & 1 & \\
\hline \multirow{2}{*}{ Lingkungan } & \multirow{2}{*}{9.117} & \multirow{2}{*}{0.001} & \multirow{2}{*}{-3.75} & \multirow{2}{*}{-0.375} & 0.00 & 0.72 & \multirow{2}{*}{$74.8 \%$} \\
\hline & & & & & 3 & 4 & \\
\hline
\end{tabular}

Berdasarkan data diatas pada aspek fisik diperoleh $F=4.266$ dan $p=0.024$ $(\mathrm{p}<0.05)$, yang artinya terdapat interaksi antara waktu (pretest, posttest, dan follow up) dan kelompok (eksperimen dan kontrol). Interaksi menunjuk- 
kan bahwa perubahan skor pretest menuju posttest pada kedua kelompok adalah berbeda secara signifikan. Perubahan aspek fisik pada kelompok eksperimen (group 1) juga signifikan (MD $=-2, \mathrm{p}=0.002 ; \mathrm{p}<0.05)$ sedangkan perubahan aspek fisik pada kelompok kontrol tidak signifikan (MD $=0.25, \mathrm{p}=$ 0.634; $p<0.05)$. Hal ini menunjukkan bahwa pelatihan kebersyukuran yang diberikan pada kelompok eksperimen efektif dalam meningkatkan aspek fisik hidup guru inklusi. Pelatihan kebersyukuran juga meningkatkan aspek fisik guru inklusi sebesar $52.8 \%$.

Pada aspek psikologis diperoleh $\mathrm{F}$ $=4.589$ dan $p=0.019(p<0.05)$, yang artinya terdapat interaksi antara waktu (pretest, posttest, dan follow up) dan kelompok (eksperimen dan kontrol). Interaksi menunjukkan bahwa perubahan skor pretest menuju posttest pada kedua kelompok adalah berbeda secara signifikan. Perubahan aspek psikologis pada kelompok eksperimen (group 1) juga signifikan $(M D=-2.5, p=0.003 ; p<$ 0.05) sedangkan perubahan aspek psikologis pada kelompok kontrol tidak signifikan $(M D=0.00, p=1 ; p<$ 0.05). Hal ini menunjukkan bahwa pelatihan kebersyukuran yang diberikan pada kelompok eksperimen efektif dalam meningkatkan aspek psikologis hidup guru inklusi. Pelatihan kebersyukuran juga meningkatkan aspek psikologis guru inklusi sebesar $48 \%$.

Pada aspek sosial diperoleh $\mathrm{F}=$ 3.556 dan $p=0.042(p<0.05)$, yang artinya terdapat interaksi antara waktu (pretest, posttest, dan follow up) dan kelompok (eksperimen dan kontrol). Interaksi menunjukkan bahwa perubahan skor pretest menuju posttest pada kedua kelompok adalah berbeda secara signifikan. Ada perubahan aspek sosial pada kelompok eksperimen (group 1) (MD = 0.625), tetapi perubahan ini tidak signifikan karena nilai $p>0.05$, yaitu 0.128. Pada kelompok kontrol tidak ada perubahan yang signifikan pada aspek sosial $(M D=0.125, p=0.751 ; p<$ 0.05). Artinya, secara kuantitatif tidak ada perubahan yang signifikan pada aspek sosial kelompok eksperimen. Hal ini disebabkan jumlah aitem aspek sosial pada skala kualitas hidup hanya terdapat dua aitem. Namun, secara kualitatif perubahan pada aspek sosial ini yang paling mereka rasakan. Mereka merasakan adanya dukungan sosial dari lingkungan sekitar dapat membantu mereka untuk lebih bersyukur yang berdampak meningkatnya kualitas hidup mereka. Pelatihan kebersyukuran juga meningkatkan aspek sosial guru inklusi sebesar $42.1 \%$. 
Pada aspek lingkungan diperoleh $\mathrm{F}$ $=9.117$ dan $p=0.001(p<0.05)$, yang artinya terdapat interaksi antara waktu (pretest, posttest, dan follow up) dan kelompok (eksperimen dan kontrol). Interaksi menunjukkan bahwa perubahan skor pretest menuju posttest pada kedua kelompok adalah berbeda secara signifikan. Perubahan aspek lingkungan pada kelompok eksperimen (group 1) juga signifikan (MD $=-3.75, \mathrm{p}=0.003$; $\mathrm{p}<0.05)$ sedangkan perubahan aspek lingkungan pada kelompok kontrol tidak signifikan $(\mathrm{MD}=-0.375, \mathrm{p}=0.724 ; \mathrm{p}$ $<$ 0.05). Hal ini menunjukkan bahwa pelatihan kebersyukuran yang diberikan pada kelompok eksperimen efektif dalam meningkatkan aspek lingkungan hidup guru inklusi. Pelatihan kebersyukuran juga meningkatkan aspek lingkungan guru inklusi sebesar $74.8 \%$.

\section{PEMBAHASAN}

Hasil uji hipotesis pada penelitian ini menunjukkan adanya perbedaan yang signifikan antara subjek yang mengikuti pelatihan kebersyukuran dengan subjek yang tidak mengikuti pelatihan kebersyukuran. Hal ini ditunjukkan dengan adanya perbedaan yang signifikan antara skor prates dan pascates kualitas hidup pada kelompok eksperimen dan kelom- pok kontrol $(F=8.082, p=0.002 ; p<$ 0.05). Pelatihan kebersyukuran juga efektif dalam meningkatkan kualitas hidup, hal ini dilihat dari hasil analisis pada kelompok eksperimen $(\mathrm{MD}=-9.5, \mathrm{p}=$ 0.00; $p<0.05)$ ) dan pada kelompok kontrol $(M D=-0.625, p=0.762 ; p<$ 0.05). Pelatihan kebersyukuran ini memiliki sumbangan efektif sebesar $71 \%$ untuk meningkatkan kualitas hidup guru inklusi.

Hasil analisis diatas menunjukkan bahwa guru inklusi yang mendapatkan pelatihan kebersyukuran mengalami peningkatan kualitas hidup dibandingkan dengan guru inklusi yang tidak mendapatkan pelatihan kebersyukuran. Hal ini sesuai dengan penelitian Froh, Seffick, dan Emmons (2008) bahwa individu yang sering merasakan dan mengungkapkan rasa terima kasih akan lebih menikmati pekerjaan, lebih optimis dan energik, dan lebih membantu atau mendukung orang lain daripada orang yang tidak mengalami rasa bersyukur yang berhubungan dengan kualitas hidup. Bersyukur menumbuhkan pengalaman hidup yang positif dari pengalaman hidup atau situasi yang dihadapi, sehingga seseorang dapat mengeluarkan kepuasan secara maksimal dan menikmati keadaan mereka. Bersyukur juga merupakan strategi koping. Dalam 
bersyukur seseorang menafsirkan secara positif permasalahan hidup (Arief \& Habibah, 2015).

Berterima kasih atas kehidupan dapat menimbulkan ketenangan pikiran, kebahagiaan, kesehatan fisik, dan hubungan pribadi lebih memuaskan (Emmons \& McCullough, 2003). Sesuai dengan penelitian Froh, Seffick, dan Emmons (2008) diketahui bahwa pandangan kebersyukuran tidak memerlukan kehidupan yang penuh kenyamanan materi melainkan sikap interior bersyukur terlepas dari kondisi kehidupan.

Subjek penelitian mengalami perubahan yang positif setelah mendapatkan pelatihan kebersyukuran. Mereka mulai dapat menikmati pekerjaan dan kehidupannya, serta mampu mengambil makna dari setiap peristiwa yang mereka alami, walaupun itu merupakan peristiwa negatif. Romdhon (2010) dalam penelitiannya menyatakan bahwa rasa syukur dapat bersumber dari persepsi positif seseorang terhadap pengalaman yang dialaminya. Nikmat yang diberikan Tuhan tidak selalu datang dalam wujud peristiwa yang positif menurut manusia, tetapi dengan syukur seseorang diajarkan untuk tetap mengambil keuntungan atau mempunyai persepsi positif dari peristiwa yang tampaknya negatif. Romdhon (2010) juga menyatakan bahwa keber- syukuran tidak hanya berguna ketika individu mengalami atau menerima sesuatu yang menyenangkan. Namun, kebersyukuran juga bisa berfungsi sebagai koping ketika individu mengalami situasi menekan dan kejadian yang tidak menyenangkan.

Penelitian terkini juga menunjukkan bahwa merasa syukur memiliki banyak manfaat dan keuntungan, baik dari segi emosional, fisik, dan interpersonal (Emmons \& McCullough, 2003). Orang yang memiliki rasa syukur tinggi cenderung memiliki tingkat emosi positif yang tinggi dan tingkat emosi negatif yang rendah seperti kecemasan, iri (McCullough dkk., 2002), tingkat stress dan depresi yang rendah (McCullough, dkk, 2004; Watkins, dkk, 2003). Selain itu, studi Emmons dan McCullough (2003) menunjukkan bahwa orang-orang yang bersyukur cenderung lebih sedikit mengalami gejala penyakit fisik daripada mereka yang tidak bersyukur. Dalam hal interpersonal, orang yang bersyukur cenderung lebih prososial, lebih empatik, memaafkan dan membantu (McCullough dkk., 2002). Di samping itu, mereka juga memiliki persepsi dukungan sosial yang lebih tinggi (Wood dkk., 2008).

Perubahan yang dialami subjek juga disebabkan karena adanya proses refleksi, berbagi, dan diskusi selama 
proses pelatihan. Hakikat refleksi diri di dalam sebuah pelatihan adalah memantulkan atau menghadirkan kembali dalam batin seseorang mengenai berbagai pengalaman yang sudah terjadi untuk menemukan makna dan nilainya yang lebih dalam. Sementara berbagi dan diskusi adalah membagikan pikiran dan atau perasaan yang muncul sebagai hasil refleksi kepada orang lain dalam kegiatan belajar bersama (Supratiknya, 2008). Dari proses refleksi, berbagi, dan diskusi tersebut membuat tiap peserta menyadari bahwa mereka tidak sendiri. Mereka menyadari bahwa peserta lain juga merasakan apa yang mereka rasakan. Mereka mengetahui bahwa guru lain juga merasakan beratnya pekerjaan mereka. Selain itu, peserta juga belajar satu sama lain dan menyadari bahwa ada masalah yang lebih berat dibandingkan dengan masalah yang mereka hadapi. Mereka juga saling belajar bagaimana cara menghadapi masalah, sehingga akhirnya mereka memperoleh pencerahan dari masing-masing peserta. Sehingga akhirnya menimbulkan tekad yang kuat dalam diri peserta untuk melakukan perubahan diri yang lebih baik di dalam kehidupannya.

Pada pelatihan kebersyukuran ini peserta diberikan pekerjaan rumah menulis peristiwa-peristiwa yang terjadi dalam kehidupan mereka dan mengambil makna positif dari peristiwa-peristiwa yang mereka alami sehingga mereka dapat merefleksikan pengalaman-pengalaman mereka tersebut. Pekerjaan rumah berupa menulis pengalaman ini merupakan salah satu proses yang dapat meningkatkan kualitas hidup mereka. Hal ini sesuai dengan penelitian Emmons dan McCollough (2003) yang menyatakan individu yang menulis gratitude journal setiap minggunya secara teratur dilaporkan memiliki lebih sedikit gejala penyakit fisik, merasa lebih baik mengenai hidupnya secara keseluruhan, dan lebih optimis mengenai kehidupan mereka selama satu minggu ke depan. Partisipan yang bersyukur secara teratur dilaporkan lebih sering menolong seseorang dengan masalah pribadi atau menawarkan dukungan emosional kepada orang lain di lingkungan sosialnya.

\section{SIMPULAN DAN SARAN}

\section{Simpulan}

Berdasarkan hasil analisis data diperoleh bahwa guru inklusi yang mendapatkan pelatihan kebersyukuran mengalami peningkatan kualitas hidup dibandingkan dengan guru inklusi yang tidak mendapatkan pelatihan kebersyukuran. Dengan demikian dapat disim- 
pulkan bahwa pelatihan kebersyukuran efektif dalam meningkatkan kualitas hidup guru inklusi.

\section{Saran}

Subjek diharapkan untuk mengaplikasikan hasil dari proses pelatihan ke dalam kehidupan sehari-hari agar manfaat yang diperoleh lebih terasa dan diharapkan dapat memperbaiki tingkat kualitas hidup guru inklusi.

Peneliti selanjutnya dapat membuat pelatihan kebersyukuran dengan pertemuan lebih banyak, tetapi dengan waktu yang lebih singkat tiap pertemuannya. Hal ini untuk mencegah peserta yang jenuh dan kelelahan akibat waktu yang terlalu panjang di setiap pertemuan. Sehingga diharapkan peserta dapat lebih memahami dan lebih mampu menemukan makna dibalik setiap peristiwa.

\section{DAFTAR PUSTAKA}

Al-Jauziyyah, I.Q. (2010). Sabar dan Syukur: Menguak Rahasia di Balik Keutamaan Sabar dan Syukur. Semarang: Pustaka Nuun.

Arief, M. F., \& Habibah, N. (2015). Pengaruh Strategi Aktivitas (Bersyukur dan Optimis) terhadap Peningkatan Kebahagiaan pada
Mahasiswa S1 Pendidikan Guru Sekolah Dasar. Seminar Psikologi dan Kemanusiaan UMM.

Arrofiq, A. (2013). Makna Syukur Guru Tidak Tetap pada Sekolah Dasar Muhammadiyah di Surakarta. Naskah Publikasi Psikologi dan Pendidikan Agama Islam Universitas Muhammadiyah Surakarta.

Chadha, M., \& Pandey, N. (2015). A Study of Quality of Life among Government and Non-Government Secondary School Teachers. Indian Journal of Health and Wellbeing. 6(1), 37-41.

Chan, D. W. (2010). Teacher Burnout Revisited: Introducing Positive Intervention Approaches Based on Gratitude ad Forgiveness. Educational Research Journal. 25(2).

Damasio, B. F., Melo, R. L. P., \& Siva, J. P. (2013). Meaning in Life, Psychological Well-Being and Quality of Life in Teachers. Paideia. 23(54), 73-82.

Elisa, S., \& Wrastari, A. T. (2013). Sikap Guru terhadap Pendidikan Inklusi Ditinjau dari Faktor Pembentuk Sikap. Jurnal Psikologi Perkembangan dan Pendidikan. 2(1).

Emmons, R. A., \& McCullough, M. E. (2003). Counting Blessings Versus Burdens: An Experimental Investigation of Gratitude and Subjective 
Well-Being in Daily Life. Journal of Personality and Social Psychology. 84(2), 377-389.

Froh, J. J., Sefick, W. J., \& Emmons, R. A. (2008). Counting Blessings in Early Adolescents: An Experimental Study of Gratitude and Subjective Well-Being. Journal of School Psychology. 46, 213-233.

Hull, J. R. (2005). General Classroom and Special Education Teachers' Attitudes toward and Perceptions of Inclusion in Relation to Student Outcomes. Disertation The University of West Florida.

Hutton, R. S. (2008). Enhancing Teacher Learning in Inclusion. Thesis Massey University.

Ilgan, A., Ozu-Cengiz, O., Ata, A., \& Akram, M. (2015). The Relationship Beteen Teachers' Psychological Well-Being and Their Quality of School Work Life. The Journal of Happiness \& Well-Being. 3(2), 159-181.

Kongchao, H., Min, L., Yongbo, Z., \& Xiaoping, Y. (2015). Research on Professional Life Quality of Preschool Teachers in Chinese Poverty Counties: Job Satisfaction' Perspective. Asian Social Science. 11(9).

McKeating, E. (2013). Including Children with ASD in Regular Kindergarten and First Grade Classrooms: Teacher Attitudes, Child Progress and Classroom Quality. Disertation University of Pittsburgh.

Muwana, F. C. (2013). Zambian Student Teachers' Attitudes toward Including Students with Disabilities in General Education Classrooms. Disertation University of Illinois.

Ni'matuzahroh. (2015). Analisis Kesiapan Guru dalam Pengelolaan Kelas Inklusi. Seminar Psikologi \& Kemanusiaan.

Shabani, E., \& Shamir, A. S. (2014). High School Teachers Sensation Seeking, Quality of Life and Hope of Life. International Journal of Education and Applied Sciences. 1(6), 287296.

Supratiknya, A. (2008). Merancang Program dan Modul Psikoedukasi. Yogyakarta: USD Press.

Stark, R., Gordon-Burns, D., Purdue, K., Rarere-Briggs, B., \& Turnock, K. (2010). Other Parents' Perceptions of Disability and Inclusion in Early Childhood Education: Implications for The Teachers' Role in Creating Inclusive Communities. He Kupu The World.

Watkins, P. C., Woodward, K., Stone, T., \& Kolts, R. L. (2003). Gratitude and Happiness: Development of A Measure of Gratitude, and 
Relationships with Subjective WellBeing. Social Behavior and Personality. 31(5), 431-452.

Wicaksono, A. R. (2013). Hubungan antara Kebersyukuran dengan Efikasi Diri pada Guru Tidak Tetap di Sekolah Dasar Muhammadiyah. Naskah Publikasi. Surakarta: Universitas Muhammadiyah Surakarta.
Wood, A. M., Maltby, J., Gillett, R., Linley, P. A., \& Joseph, S. 2008. The role of gratitude in the development of social support, stress, and depression: Two longitudinal studies. Journal of Research in Personality, 42, 854871. 